\title{
Effect of Isoflurane on the Hearing in Mice
}

\author{
Joung Uk Kim¹, Yun Suk Ahn², Jin Kyung Suh² and Jong Woo Chung ${ }^{2}$ \\ ${ }^{1}$ Departments of Anesthesiology and Pain Medicine, ${ }^{2}$ Otolaryngology, Asan Medical Center, University of Ulsan College of Medicine, \\ Seoul, Korea
}

\begin{abstract}
Received November 15, 2011
Revised December 20, 2011

Accepted January 3, 2012
\end{abstract}

Address for correspondence

Jong Woo Chung, MD, PhD

Department of Otolaryngology,

Asan Medical Center, University

of Ulsan College of Medicine,

88 Olympic-ro 43-gil, Songpa-gu,

Seoul 138-736, Korea

Tel +82-2-3010-3718

Fax +82-2-489-2773

E-mail jwchung@amc.seoul.kr
Background and Objectives: The aim of this study was to investigate the relationship between inhalation anesthetics and hearing in mice. Materials and Methods: As inhalation anesthetics, isoflurane was used. Auditory brainstem response and distortion product otoacoustic emission were used as measurement of hearing. Mice were divided into 2 groups. 'Isoflurane group' consisted of mice that were anesthetized with an inspired concentration of $2.0 \mathrm{vol} \%$ isoflurane with $2 \mathrm{~L} / \mathrm{min}$ of oxygen $(n=10)$. 'Control group' consisted of mice that were anesthetized with ketamine and xylazine $(n=10)$. Results: Auditory brainstem response thresholds in mice anesthetized with ketamine and xylazine was not different from those in mice anesthetized with isoflurane. Threshold of DPOAE was higher in mice with isolurane than with ketamine and xylazine. Changes of efferent control may be induced by isoflurane and consequently change the threshold of DPOAE in mice. Conclusions: These results infer that, there was a change of central nervous system induced by inhalation anesthetics, this change also can be applied to the strategies for prevention of hearing loss.

Korean J Audiol 2012;16:14-17

KEY WORDS: Hearing · Anesthetics · Central nervous system · Efferent control.

\section{Introduction}

Inhalation anesthetics, such as isoflurane and halothane, can reduce the threshold shift of hearing in noise induced hearing loss model of mice. ${ }^{1,2)}$ Apoptosis of inner ear which was shown in inner ear of noise exposed mice was also reduced in mice with isoflurane anesthetics. Though the mechanism of these protective roles was not known yet, anti-oxidant effect of isoflurane and changes of central nervous system were suggested. ${ }^{3,4)}$

The protective role in noise-exposed mice was also shown in pentobarbital. Though the protection of hearing against noise was larger in isoflurane than in pentobarbital, modulation of central nervous system should be considered because pentobarbital is known to have little anti-oxidant effect. ${ }^{3,4)}$

Both of isoflurane and pentobarbital have a muscle relaxant effect. Relaxation of stapes muscle elevated the threshold of stapedial reflex which is protective mechanism of inner ear from noise sound. This means the reduction of protective role from noise in anesthetized mice. However, the reported data showed the contrary results. ${ }^{5-10)}$ Taken together, the study of the relationship between anesthesia and hearing or hearing loss is needed.
Authors aimed to investigate the relationship between anesthetics and hearing in mice. As anesthetics, isoflurane was used. Auditory brainstem response and distortion product otoacoustic emission were used as measurement of hearing.

\section{Materials and Methods}

BALB/c mice (4 weeks of age), which have normal Preyer's reflex and a normal hearing threshold, were purchased from Orient Charles River Technology (Seoul, Korea) and were housed in cages and maintained in environmentally-controlled rooms with a $12 \mathrm{~h}$ light/dark cycle. Food and water were available ad libitum. All animal experiments were carried out on the approval was obtained from the Animal Care Committee of University of Ulsan College of Medicine. The care and use of the animals reported in this study were in accordance with the guidelines of the Laboratory Animal Unit of Asan Institute for Life Sciences.

Mice were divided into 2 groups. 'Isoflurane group' consisted of mice that were anesthetized with an inspired concentration of $2.0 \mathrm{vol} \%$ isoflurane with $2 \mathrm{~L} / \mathrm{min}$ of oxygen $(\mathrm{n}=10)$. 'Control group' consisted of mice that were anesthetized with intramuscular ketamine hydrochloride $(30 \mathrm{mg} / \mathrm{kg})$ and intra- 
peritoneal xylazine $(2 \mathrm{mg} / \mathrm{kg}$ ) during measurement of hearing $(\mathrm{n}=10)$.

The body temperature of mice was monitored with rectal temperature probe equipped in the continutous monitoring device (Datex-Ohmeda, S/5, Bradford, UK) to rule out the effect of whole body cooling or heating. The mice were maintained at a rectal temperature of $35-37^{\circ} \mathrm{C}$ with circulating-water mattress cooling (Blanketrol II, Cincinnati Sub-Zero Co., Cincinnati, OH, USA) and heat lamp.

The hearing level of each mouse was analyzed by measuring the auditory brainstem response (ABR) threshold using an auditory evoked potential workstation (Tucker-Davis Technologies, Alachua, FL, USA). During anesthesia, each ear was stimulated with a probe sealed into the ear canal. To elicit the ABR, click sounds were generated with 1-ms rise/fall times and 2-ms plateaus. To permit recording, subdermal stainlesssteel needle electrodes were placed at the vertex and ventrolateral to the left and right ears. ABR waveforms were recorded for $10 \mathrm{~ms}$ at a sampling rate of $11.1 \mathrm{kHz}$ using bandpass filter settings of $0.5-3 \mathrm{kHz}$. Generally, responses from 512 sweeps were averaged to compute a resulting evoked potential. ABR waveforms were recorded in 5-dB steps by decreasing stimulus intensity from the maximum tone-pip level. ABR threshold was determined as the lowest intensity at which a $\mathrm{V}$ wave was identified. All waveforms were stored for off-line analysis by an observer blinded to treatment, to obtain average thresholds. Responses were recorded at $4 \mathrm{kHz}, 8 \mathrm{kHz}, 16 \mathrm{kHz}$, and 32 $\mathrm{kHz}$. Hearing thresholds are shown as means.

Distortion product otoacoustic emissions (DPOAE) measurements were recorded using an ER10B + low-noise microphone and a probe housed in the same coupler as the $\mathrm{fl}$ and f2 speakers. The output was passed through an MA3 microphone amplifier and through the RP2.1 A/D converter, where it was sampled at $200 \mathrm{kHz}$. The magnitude of the $2 \mathrm{f} 1 \mathrm{Yf} 2$ distortion product was obtained by fast Fourier transformation of the resulting output using the TDT BioSig software (TuckerDavis Technologies, Alachua, FL, USA). Distortion product otoacoustic emissions thresholds were calculated at 5.6, 8, 11.3, and $16 \mathrm{kHz}$.

Stimuli for ABR and DPOAE measurements were calibrated using an ACO calibration kit, EC1 speaker with 0.2$\mathrm{mL}$ coupler, and sigCalRP (Tucker-Davis Technologies).

SPSS version 18 (SPSS Inc., Chicago, IL, USA) was used for data analysis. We used student t-test for analyzing the group difference.

\section{Results}

Average ABR thresholds were $18.0 \pm 5.9$ at $4 \mathrm{kHz}, 21.5 \pm$

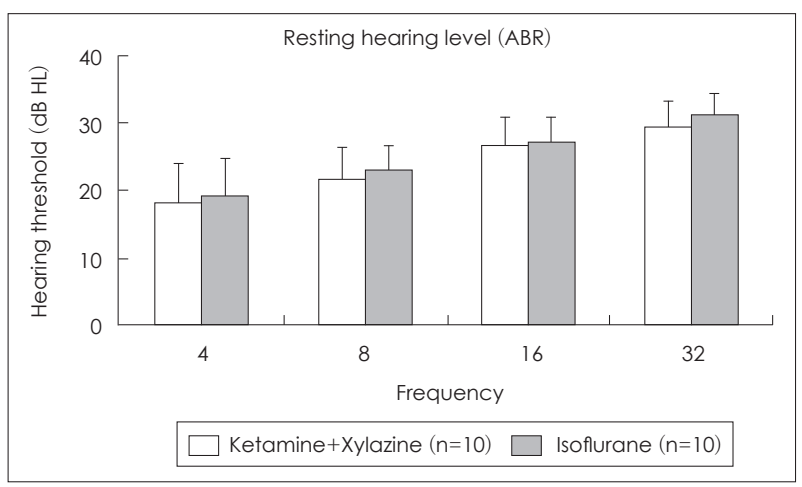

Fig. 1. Changes of hearing level measured by $A B R$ according to the anesthesia type. ABR: auditory brainstem response.

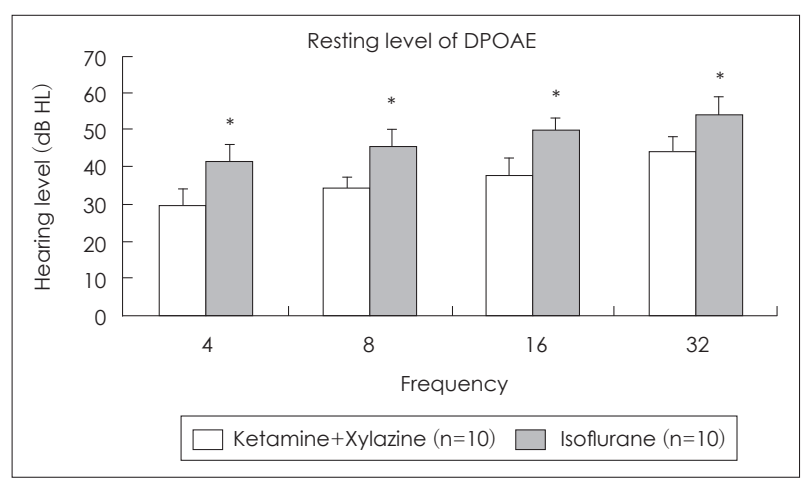

Fig. 2. Changes of hearing level measured by DPOAE according to the anesthesia type. ${ }^{*} p<0.05$. DPOAE: distortion product otoacoustic emissions.

4.7 at $8 \mathrm{kHz}, 26.5 \pm 4.1$ at $16 \mathrm{kHz}$, and $29.0 \pm 3.9$ at $32 \mathrm{kHz}$ in mice anesthetized with ketamine and xylazine. In mice anesthetized with isoflurane, ABR thresholds were 19.0 \pm 5.7 , $23.0 \pm 3.5,27.0 \pm 3.5$, and $31.0 \pm 3.2$, respectively. ABR thresholds were not different from each other among both groups (Fig. 1). Average thresholds of DPOAE were $29.5 \pm 4.4$ at 4 $\mathrm{kHz}, 34.0 \pm 3.2$ at $8 \mathrm{kHz}, 37.5 \pm 4.2$ at $16 \mathrm{kHz}$, and $44.0 \pm 3.9$ at $32 \mathrm{kHz}$ in mice anesthetized with ketamine and xylazine. In mice anesthetized with isoflurane, DPOAE thresholds were $41.0 \pm 5.2,45.5 \pm 5.0,49.5 \pm 3.2$, and 54.0 \pm 5.2 , respectively. In mice anesthetized with isoflurane, DPOAE thresholds were higher than those in mice with ketamine and zylazine $(p<0.05$ in all frequencies)(Fig. 2).

\section{Discussion}

The effect of anesthesia on ABR is well known. The propofol is known to increase ABR latencies whereas amplitudes are decreased. It has been shown that isofurane is responsible for an increase of ABR latencies whereas it does not modify the amplitudes. ${ }^{11,12)}$

And propofol is known to decrease both intracranial pressure and cerebral blood flow, but without modifying either 
cerebral blood flow autoregulation to hemodynamic variation, or vasomotor reaction to $\mathrm{PaCO}_{2}$ variation. ${ }^{13)}$ In contrast, isoflurane has been demonstrated to diminish cerebral blood flow and cerebral blood flow autoregulation. ${ }^{14)}$

In this study there was no change of ABR threshold in mice with isoflurane, so the function of inner hair cells may not be changed by anesthesia with isoflurane. The results shown in this study could not draw the exact mechanism of the DPOAE change. However, there were couple of reports on the change of DPOAE.

Harel, et al., ${ }^{15)}$ reported the change of transient evoked otoacoustic emission (TEOAE) by general anesthesia. They showed about $30 \%$ increase of threshold in mice with general anesthesia. Likewise, there was 20-35\% increase of DPOAE threshold in $4-32 \mathrm{kHz}$. From these results, isoflurane may have an effect on efferent cochlear control and induced increase of DPAOE threshold.

Ferber-Viart, et al., ${ }^{16)}$ reported a decrease of TEOAE level by general anesthesia in human study. They proposed the hemodynamic changes in general anesthesia as a responsible cause of TEOAE change. They, however, could not exclude the pharmacological properties of anesthetics. To solve these suggestions, contralateral suppression study is needed. In this study, we didn't perform contralateral suppression study and we only could conclude that the change of cochlear efferent control may be one of the mechanisms of DPOAE change. ${ }^{17-20)}$

Chung, et al. ${ }^{1)}$ reported that isoflurane and halothane anesthesia could protect noise induced hearing loss in mice. They explained the reduction of the production of reactive oxygen species and antagonistic effect on N-methyl-D-aspartate receptor as possible mechanisms of the protection. They also proposed the protective effect through central processes as one of the mechanisms. Because volatile anesthetics have depressive effect on central function, medial olivocochlear bundle system can be a target of these anesthetics.

The stapedial reflex (SR) is an autonomic reflex that protects the inner ear against very loud noises. The first nuclear connection of the cochlear nerve is at the brain stem and the neurotransmitters involved are not precisely known, but aspartate, glutamate, acetylcholine and noradrenaline (norepinephrine) have been suggested. The same neural mediators have been found in the efferent nuclei of the stapedial reflex arch. The transmitter in the motor endplate is acetylcholine. Because of its neuroanatomical structure, anaesthetic agents, which have a sedative or depressive effect on the central nervous system, may affect the SR. ${ }^{21)}$

Taken together, changes of DPOAE in mice anesthetized with isoflurane can be explained by the change of efferent control. The exact mechanism of the control needs further study.

\section{Conclusion}

If there was a change of central nervous system induced by the anesthetics, this change also can be applied to the strategies for prevention of hearing loss.

\section{Acknowledgments}

This work was supported by the Korean Research Foundation grant funded by the Korean Government (MOEHRD, Basic Research Promotion Fund; KF-2008-314-E00189).

\section{REFERENCES}

1) Chung JW, Ahn JH, Kim JY, Lee HJ, Kang HH, Lee YK, et al. The effect of isoflurane, halothane and pentobarbital on noise-induced hearing loss in mice. Anesth Analg 2007;104:1404-8.

2) Kim JU, Lee HJ, Kang HH, Shin JW, Ku SW, Ahn JH, et al. Protective effect of isoflurane anesthesia on noise-induced hearing loss in mice. Laryngoscope 2005;115:1996-9.

3) Sha SH, Schacht J. Formation of reactive oxygen species following bioactivation of gentamicin. Free Radic Biol Med 1999;26:341-7.

4) Sha SH, Schacht J. Antioxidants attenuate gentamicin-induced free radical formation in vitro and ototoxicity in vivo: D-methionine is a potential protectant. Hear Res 2000;142:34-40.

5) Holmquist J, Oleander R, Hallén O. Peroperative drill-generated noise levels in ear surgery. Acta Otolaryngol 1979;87:458-60.

6) Man A, Winerman I. Does drill noise during mastoid surgery affect the contralateral ear? Am J Otol 1985;6:334-5.

7) Palva T, Kärjä J, Palva A. High-tone sensorineural losses following chronic ear surgery. Arch Otolaryngol 1973;98:176-8.

8) Parkin JL, Wood GS, Wood RD, McCandless GA. Drill- and suctiongenerated noise in mastoid surgery. Arch Otolaryngol 1980;106:92-6.

9) Rubinstein M, Pluznik N. Effect of anesthesia on susceptibility to acoustic trauma. Ann Otol Rhinol Laryngol 1976;85(2 pt.1):276-80.

10) Slepecky N. Overview of mechanical damage to the inner ear: noise as a tool to probe cochlear function. Hear Res 1986;22:307-21.

11) Lloyd-Thomas AR, Cole PV, Prior PF. Quantitative EEG and brainstem auditory evoked potentials: comparison of isoflurane with halothane using the cerebral function analysing monitor. $\mathrm{Br} \mathrm{J}$ Anaesth 1990;65:306-12.

12) Manninen PH, Lam AM, Nicholas JF. The effects of isoflurane and isoflurane-nitrous oxide anesthesia on brainstem auditory evoked potentials in humans. Anesth Analg 1985;64:43-7.

13) Fox J, Gelb AW, Enns J, Murkin JM, Farrar JK, Manninen PH. The responsiveness of cerebral blood flow to changes in arterial carbon dioxide is maintained during propofol-nitrous oxide anesthesia in humans. Anesthesiology 1992;77:453-6.

14) Hoffman WE, Edelman G, Kochs E, Werner C, Segil L, Albrecht RF. Cerebral autoregulation in awake versus isoflurane-anesthetized rats. Anesth Analg 1991;73:753-7.

15) Harel N, Kakigi A, Hirakawa H, Mount RJ, Harrison RV. The effects of anesthesia on otoacoustic emissions. Hear Res 1997;110:25-33.

16) Ferber-Viart C, Preckel MP, Dubreuil C, Banssillon V, Duclaux R. Effect of anesthesia on transient evoked otoacoustic emissions in humans: a comparison between propofol and isoflurane. Hear Res 1998;121:53-61.

17) Giraud AL, Collet L, Chéry-Croze S. Suppression of otoacoustic emission is unchanged after several minutes of contralateral acoustic stimulation. Hear Res 1997;109:78-82.

18) Katona G, Büki B, Farkas Z, Pytel J, Simon-Nagy E, Hirschberg J. Transitory evoked otoacoustic emission (TEOAE) in a child with profound hearing loss. Int J Pediatr Otorhinolaryngol 1993;26:263-7.

19) Lisowska G, Smurzynski J, Morawski K, Namyslowski G, Probst R. 
Kim JU, et al.

Influence of contralateral stimulation by two-tone complexes, narrow-band and broad-band noise signals on the 2f1-f2 distortion product otoacoustic emission levels in humans. Acta Otolaryngol 2002; 122:613-9.

20) Pérez N, Fernández S, Espinosa JM, Alcalde J, García-Tapia R. [Dis- tortion of otoacoustic emission]. Acta Otorrinolaringol Esp 1993;44: 265-72.

21) Guven S, Tas A, Adali MK, Yagiz R, Alagol A, Uzun C, et al. Influence of anaesthetic agents on transient evoked otoacoustic emissions and stapedius reflex thresholds. J Laryngol Otol 2006;120:10-5. 